\title{
Doubts greet violence-research funding plea
}

Washington. A substantial increase in the sums allocated in the United States to violence-related research has been recommended by an expert panel in a report last week to Harold Varmus, the director of the National Institutes of Health (NIH).

The panel points out that violence should be considered a major public health problem, as it is the second leading cause of death among American youth. And African American men are seven times more likely than other Americans to be the victims of homicide, it says.

But both Varmus and the members of his advisory committee, at a meeting at which the panel's report was made public, expressed scepticism about the value of such an increase without a clear plan for how the extra money would be spent.

The expert panel was established last year by Bernadine Healy, Varmus's predecessor as NIH director, in response to controversy surrounding a grant for a conference on genetic factors and crime, made by the National Center for Human Genome Research to the University of Maryland.

A brochure produced by the university about the conference angered members of the African American community, particularly at Howard University in Washington, DC. The main complaint was that inadequate attention was being paid to the many factors apart from genetics - for example poverty - that are causes of violence.

Healy suspended the grant for the conference on the grounds that the controversy would not allow a proper scientific debate to be held (a decision that was later overturned

\section{IMAGE UNAVAILABLE FOR COPYRIGHT REASONS}

Despite decades of research into its causes, violence remains on the increase in the US.

by an appeals board of the Public Health Service). At the same time, she decided that the NIH should take a close look at all violence-related research carried out in its institutes.

Although the controversial origins of the report were barely touched on at last week's meeting, Don Wood, professor of neurology at Howard University Hospital, commented on the absence from its 19 recommendations of any explicit statement identifying a particular area of questioning as a "no go" area. "I think that this should be explicitly stated," he said.

Thomas Murray, co-chair of the panel and director of the Center for Biomedical Ethics at Case Western Reserve University, in Cleveland, Ohio, preferred to emphasize his proposal that funding should double — or even triple — from its current level of $\$ 58$ million a year. He also called for interdisciplinary research and the introduction of a new peer-review panel qualified to evaluate such research.

But several members of the advisory committee appeared unimpressed by the report's conclusions. Among them was Joshua Lederberg, of the Rockefeller University in New York, who claimed "an intense sense of déjà vu". According to Lederberg he could have heard the same conclusions 25 years ago when he sat as a member of an advisory panel to the National Institute of Mental Health. "We need to know what we have learned to date," he said. "We need some focus, vision and working hypotheses in this area."

Other members of the advisory committee felt it should have paid more attention to basic biomedical research. Varmus himself seemed less than enthusiastic about its findings. He questioned why the report contained no assessment of the achievements of violence-related research to date, or details of how the extra money should be spent.

Helen Gavaghan

\section{. . . as NIH tightens up on academic-industry deals}

Washington. Close scrutiny should be given to industrial research contracts signed by any academic research group if the contract represents more than 20 per cent of that group's overall budget, according to proposed conflict-of-interest guidelines published last week.

Other situations that should trigger such scrutiny include those where financial support from industry exceeds $\$ 5$ million in one year - or $\$ 50$ million in total - and where the licensing rights cover all, or a substantial proportion, of the technologies developed from the group's research in a particular field.

Furthermore, an agreement lasting for five or more years should also receive close attention, according to the guidelines on academic-industry agreements presented

\section{Italian science}

Italy's new minister for universities and research is Stefano Podestà, and not Bodestà, as published in our issue of 19 May $(369,175 ; 1994)$. Also, the proposals put forward by his predecessor, Umberto Colombo, would increase spending on research and development from 1.4 per cent to 1.6 per cent of the gross national product, not 1.6 per cent to 2.0 per cent as printed. last week to Harold Varmus, the director of the National Institutes of Health, and now being circulated for comment in the academic community.

The proposed guidelines have been drawn up by an ad hoc advisory panel to the NIH in the wake of last year's public controversy over an agreement signed between the Scripps Research Institute in San Diego, California, and the Swiss company Sandoz Pharmaceutical.

In principle, such deals have long been encouraged by the government, particularly after the passage of the Bayh-Dole Act in 1980 , which sought to boost the transfer of research results from universities to the marketplace. This act allows universities to retain title to inventions resulting from federally funded research, and to licence the inventions to industry for development.

There are now some 7,000 licensing agreements of various kinds with industry. Most have proceeded without controversy. But the Scripps-Sandoz deal raised congressional hackles because it effectively gave Sandoz exclusive access to all publicly funded research carried out at Scripps.

Following lengthy negotiations with the legal department of the NIH, the two parties have agreed to modify their agreements. Originally Sandoz was to have paid $\$ 300$ million over 10 years for access to about $\$ 1$-billion worth of federally funded research at Scripps. The company will now pay $\$ 20$ million a year for five years, and will in return have exclusive rights to only 47 per cent of the institution's research.

Responding to criticism that the original deal was too tightly tied to the interests of a single large company, Scripps is also establishing a programme to encourage technology transfer to small businesses, which the NIH will monitor annually.

Last month, the NIH sent to Scripps what it hopes will be the last letter in the controversy. In it, Varmus wrote that, given the institution's cooperation in making research available to small businesses, the NIH hoped to reach an agreement that would obviate the need "to limit Scripps' right to federally funded inventions".

According to one NIH official, the letter is intended as a shot across the bows, indicating to other large academic institutions that there are limits to what the NIH is prepared to tolerate.

H. G. 